\title{
PENERAPAN MODEL CONTEXTUAL TEACHING AND LEARNING (CTL) PADA PEMBELAJARAN PAI DI MAN 1 SUNGAI PENUH
}

\author{
Masnur Alam \\ Institut Agama Islam Negeri (LAIN) Kerinci \\ email: masnur.alam@yahoo.com
}

\begin{abstract}
The aims of this research are to describe: (1) the advantages of Contextual Teaching and Learning (CTL) learning models; (2) Environmental material and efforts to preserve it; (3) Application of Contextual Teaching and Learning learning models in Islamic Education. This research is a field research study, with qualitative methods. The main instruments are observation, in-depth interview, and documentation. Research findings are: (1) The Contextual Teaching and Learning learning model can increase activity, creativity, independence to find material that is learned, as well as being able to explore, discuss, understand, and apply in daily life. (2) Environmental material consisting of biotic and nonbiotic which is very beneficial for living things, the effort to preserve it is by replanting, not exploiting, cutting, burning, penetrating, use must be in accordance with environmental ethics. (3) The application of the CTL model is in accordance with the existing steps, and has succeeded in activating students to seek, understand their own environmental theories, and be motivated to actualize in everyday life and be able to correlate with real life. The Islamic Educational teacher has been able to demonstrate one of the CTL principles namely making himself a model, role model, uswatun hasanah or a good example of preserving the environment.
\end{abstract}

Keyword: Contextual Learning Model, PAI Learning, Environmental Care 


\section{PENDAHULUAN}

Dalam UU No. 20 Tahun 2003 dijelaskan bahwa pendidikan keagamaan berfungsi mempersiapkan peserta didik menjadi anggota masyarakat yang memahami dan mengamalkan nilai-nilai ajaran agamanya dan/atau menjadi ahli ilmu agama. Pendidikan agama merupakan salah satu mata pelajaran yang wajib diikuti peserta didik bersama dengan pendidikan Kewarganegaraan dan yang lainnya. Tantangan yang dihadapi dalam pendidikan agama, khususnya Pendidikan Agama Islam sebagai sebuah mata pelajaran adalah bagaimana mengimplementasikan dalam kehidupan nyata, bukan semata mengajarkan pengetahuan tentang Islam, tetapi bagaimana memahami dan mengarahkan peserta didik agar memiliki kualitas iman, takwa, dan akhlak mulia.

Akhir-akhir ini, pendidikan agama menjadi sorotan tajam dan kritik-kritik pedas atas terjadinya krisis moral, rendahnya karakter atau memburuknya akhlak siswa, sehingga peran serta pendidikan agama Islam di sekolah/madrasah sebagai pelajaran yang memberikan nilai positif terhadap peserta didik dipertanyakan. Setelah diamati, dapat dipahami bahwa, penguasaan dan pemahaman pendidikan Islam selama ini selalu berorientasi pada pencapaian target materi (pengetahuan), dan mengabaikan sikap dan pembiasaan, juga lemahnya penguasaan materi yang berhubungan dengan lingkungan hidup. Di samping itu, tak kalah penting dan sangat menentukan keberhasilan pencapaian tujuan pembelajaran, yaitu memilih salah satu model pembelajaran yang tepat dalam pembelajaran Pendidikan Agama Islam, di antaranya adalah melalui model Contextual Teaching and Learning (CTL). Dengan penerapan model kontektual murid menjadi lebih aktif, responsif dalam menggunakan pengetahuan dan keterampilan dalam kehidupan nyata sehingga siswa termotivasi tinggi untuk belajar.

Berdasarkan fenomena-fenomena di atas perlu dicari solusi, agar guru PAI tidak semata menerapkan model pembelajaran yang konvensional yang membuat peserta tidik menjadi monoton, tetapi harus mencari gagasan baru berupa alternatif dengan menerapkan model pembelajaran yang mampu membuat peserta menjadi aktif, kreatif, termotivasi untuk meningkatkan kompetensi. Maka dirasa perlu diteliti secara mendalam untuk mengetahui "Bagaimana Penerapan Model Contextual Teaching and Learning (CTL) pada Pembelajaran Pendidikan Agama Islam (PAI) di MAN 1 Sungai Penuh”. Secara lebih khusus penelitian ini terfokus pada: 1) Keunggulan dari model Contextual Teaching and Learning (CTL); 2) Materi lingkungan hidup dan upaya melestarikannya; 3) Penerapan Model Contextual Teaching and Learning pada Pembelajaran PAI. 


\section{METODOLOGI}

Penelitian ini berlokasi di Madrasah Aliyah Negeri (MAN) 1 Sungai Penuh, terletak di Jalan Pelita IV Koto Lolo Kecamatan Pesisir Bukit Kota Sungai Penuh. Lokasi ini sangat strategis mudah dijangkau melalui transfortasi umum dan pribadi, lingkungannya ASRI (aman sejuk rindang dan indah) serta nyaman untuk proses pendidikan. Informan kunci dalam peneliian ini adalah guru PAI dan beberapa orang peserta didik. Jika diperlukan, informan akan bisa meluas kepada pihak yang dirasa memiliki kaitan serta kepedulian terhadap lingkungan hidup. Teknik pengumpulan data dilakukan dengan observasi langsung, wawancara mendalam dan dokumentasi. Analisa data ditempuh sesuai dengan apa yang dikemukakan (Ali dalam Mahmud, 2011: 93) melalui tiga tahap, yaitu: a. reduksi data adalah proses memilih, menyederhanakan, memuluskan dan mengabstraksi data; b. Sajian data merupakan cara merangkai data untuk memudahkan pembuatan kesimpulan, dan c. Verifikasi adalah penjelasan tentang makna data yang dapat diajukan proposisi-proposisi yang terkait dengan data tersebut.

\section{TEMUAN}

\section{Hasil Penelitian}

Berdasarkan hasil observasi lapangan, wawancara terhadap informan dan analisis dokumen, maka dapat dikemukakan penerapan model Contextual Teaching and Learning (CTL) dilakukan melalui langkah-langkah sebagai berikut:

\section{Pendahuluan}

a. Guru Mata pelajaran PAI (Al-Quran-Hadis) Zaini, terlebih dahulu menjelaskan tema "perintah menjaga kelestarian lingkungan hidup" dengan kompetensi yang harus dicapai yaitu: "memiliki budaya menjaga kelestarian lingkungan hidup", dengan indikator siswa dapat memahami tentang: Pengertian lingkungan hidup atau ekosistem, macam-macam lingkungan, upaya melestari lingkungan, dampak dari kerusakan lingkungan, serta hubungan lingkungan dengan kebersihan, keindahan dan kesehatan.

b. Guru PAI menjelaskan prosedur pembelajaran kontektual yang akan diterapkan atau diimplementasikan. Peserta didik dibagi kepada 4 kelompok kecil, masing-masing kelompok terdiri dari 6 peserta didik. Masing-masing kelompok diminta untuk membuat tugas paper sederhana berkaitan dengan kompetensi peduli lingkungan tersebut, dengan indikator yang sudah ditetapkan.

Kelompok 1, mampu menjelaskan pengertian lingkungan hidup dan macammacam; kelompok 2, mampu menjelaskan upaya melestarikan lingkungan hidup; 
kelompok 3, mampu menjelaskan dampak dari kerusakan lingkungan; kelompok 4, mampu menghubungkan lingkungan hidup dengan kebersihan, keindahan dan kesehatan.

Kemudian guru PAI melakukan tanya jawab seputar tugas yang diberikan kepada peserta didik, menanyakan kesulitan atau kendala, sudah dapat dipahami dan dilaksanakan. Di antara siswa menjawab, kendala yang ditemui yakni keterbatasan sumber-sumber bacaan atau literatur, sehingga beberapa tugas tidak dapat dipahami secara komprehensip. Maka guru menjelaskan maksud isi dari semua indikator tersebut. Sekaligus guru telah menanamkan atau menginternalisasi nilai karakter peduli lingkungan kepada siswa.

\section{Inti}

Kegiatan inti dalam pelaksanaan model pembelajaran kontektual bermuatan karakter peduli lingkungan hidup adalah kegiatan utama peserta didik dalam melaksanakan tugasnya masing-masing. Adapun tugas yang harus dilakukan peserta didik adalah:

a. Berkunjung ke perpustakaan untuk mencari sumber-sumber bacaan yang dibutuhkan: Kelompok 1. Mencari tentang konsep dan teori yang berhubungan dengan pengertian lingkungan hidup dan macam-macam lingkungan hidup; Kelompok 2. Mencari tentang konsep dan teori yang berhubungan dengan upaya melestarikan lingkungan hidup; Kelompok 3. Mencari tentang konsep dan teori yang berhubungan dengan dampak dari kerusakan lingkungan hidup; Kelompok 4. Mencari konsep dan teori tentang hubungan lingkungan hidup dengan kebersihan, keindahan dan kesehatan.

b. Semua kelompok mencatat hasil pekerjaan lapangan di perpustakaan sesuai dengan ketentuan atau pembagian tugas yang telah ditetapkan sebelumnya. Kelompok 1 berkesimpulan lingkungan hidup atau ekologi adalah ilmu yang mempelajari interaksi makhluk hidup atau biotik (manusia, tumbuhan dan hewan/flora dan fauna) dengan lingkungan atau nonbiotik (tanah,air, udara, cahaya, suhu, iklim) dan ekosistem (hutan, padang rumput, laut, danau, kolam) dan sebagainya. Kelompok 2 berkesimpulan upaya melestari lingkungan hidup merupakan tugas manusia sebagai khalifah fi Ardh (Q.S AlBaqarah [2]: 20), dan (Q.S.Al An'am [6]: 165) bertugas untuk melestarikan bumi (Q.S. Al Anbiya' [21]: 107). Dengan cara menanam kembali, tebang satu tanam seribu. Maka dilarang berbuat kerusakan di bumi (Q.S. Al A'raf [7]: 56). Mengekploitasi, menebang, membakar dan lainnya. Kelompok 3 berkesimpulan dampak dari kerusakan lingkungan hidup adalah terancamnya semua makhluk hidup (manusia, hewan dan tumbuhan) serta 
terjadinya polusi atau pencemaran air dan tanah, udara, suara, gangguan fisiologis dan psikologis. Manusia akan merasakan sebagian dari akibat perbuatan mereka (Q.S. Ar Rum [30]: 41) dalam bentuk erosi, longsor, kelangkaan air bersih, kekeringan, banjir bandang, air laut tercemar, udara yang panas dan pengap. Kelompok 4 berkesimpulan lingkungan hidup mempunyai hubungan yang erat dengan kebersihan, kerapian, keindahan, dan kesehatan.

Lingkungan hidup (gunung, bukit yang memiliki hutan yang rindang, lebat, alami) akan mengalirkan air yang bersih dan udara yang sejuk, iklim yang normal, kebersihan akan tetap terpelihara baik secara lahir maupun batin. Al-nadzafatu min aliman (kebersihan itu bagian dari iman). Lingkungan hidup yang menghijau serta berbunga-bunga, pohon-pohon yang rindang dan bergoyang diterpa angin akan terlihat rapi dan indah untuk dipandang. Begitu juga lingkungan yang seimbang, air, udara yang bersih, kebersihan yang terpelihara dengan baik, kerapian dan keindahan yang selalu menawan akan sangat berpengaruh positif terhadap kesehatan manusia.

c. Ketika tugas lapangan selesai, maka peserta didik kembali ke dalam kelas untuk melalukan hal-hal sebagai berikut: 1) Mendiskusikan temuan lapangan mereka bersamasama sesuai kelompoknya masing-masing; 2) Masing-masing kelompok melaporkan hasil diskusi kepada kelompok yang lain; 3) Setiap kelompok menjawab pertanyaan yang diajukan oleh kelompok yang lain. Dalam kegiatan inti penerapan CTL guru terlihat mampu menginternalisasi, mentransformasi, serta mengimplementasi nilai karakter peduli lingkungan hidup. Dalam proses pembelajaran guru PAI telah menunjukkan dirinya sebagai teladan yang baik (uswatun hasanah) sebagai sosok yang menjadi panutan, contoh, dan model bagi peserta didik. Kondisi ini sudah terbiasa dilakukan sehingga akhirnya menjadi kebiasaan. Guru PAI terlihat menjadi penengah dalam diskusi dan pemutus dalam mengambil kesimpulan terhadap permasalahan yang tidak bisa diselesai oleh peserta didik.

\section{Penutup}

a. Pada tahap terakhir atau penutup, peserta didik bersama dengan guru menyimpulkan hasil observasi dan diskusi kelas seputar peduli lingkungan hidup, dengan mengacu pada indikator yang telah ditetapkan, yakni: lingkungan hidup meliputi biotik dan nonbiotik yang wajib dilestarikan untuk keselamatan hidup semua makhluk, jika terjadi kerusakan maka akan berdampak negatif atau mengancam keselamatan semua makhluk hidup tersebut, dan lingkungan hidup mempunyai hubungan yang erat dengan kebersihan, 
keindahan dan kesehatan manusia. Pada kegiatan penutup penerapan model CTL, guru PAI terlihat mampu mengimplementasi nilai karakter peduli lingkungan hidup dengan baik, dapat menjadi tauladan bagi seluruh siswanya, begitu juga para siswa telah merespons secara positip serta menjadi kepribadian, mengkarakter dalam dirinya.

b. Di samping melalui penerapan kontektual dalam pembelajaran PAI berdasarkan hasil analisis dokumen terhadap profil MAN 1 Sungai Penuh diketahui salah satu visi adalah "Berbudaya Lingkungan Hidup" serta terdapat wakil kepala madrasah bidang P2 LH (lingkungan hidup) yang bertanggung jawab dalam melestarikan lingkungan, serta salah satu kebijakannya yaitu menginstruksikan kepada seluruh warga MAN 1 untuk memelihara lingkungan dengan membuat biilboard, simbol-simbol, poster cinta lingkungan. Serta dilakukan strategi intervensi dan habituasi. Membangun budaya madrasah baik melalui kurikuler, kokurikuler dan/atau ekstrakurikuler yang terintegrasi.

c. Berdasarkan hasil wawancara diperoleh informasi bahwa seluruh warga madrasah sudah sepakat membudayakan kelestarian lingkungan, kebersihan, keindahan dan hidup sehat. Terhadap lingkungan hidup ditanami secara rapi lalu dijaga dengan baik agar bisa tumbuh dengan subur. Terhadap kebersihan baik halaman, kantor, lokal, WC, got, harus terjaga kebersihannya, maka setiap hari dilakukan gerakan sapu bersih, agar tidak ada sampah-sampah yang berserakan. Pada setiap pojok halaman dibuat taman bunga atau taman hias yang selalu dipelihara, dijaga, disirami dan dipupuk supaya subur, untuk memperindah lingkungan madrasah. Seluruh warga sudah tertanam sikap mencintai lingkungan yang berseri (bersih, sejuk, rindang, dan indah). Budaya ini tetap dijaga dan dipelihara agar tidak kendor dan menjadi kebiasaan dalam kehidupan sehari, dan ini diyakini akan berpengaruh terhadap kesehatan warga madrasah karena suasana akan menjadi sejuk di badan, indah di mata, nyaman di hati, dan tenang pada pikiran.

\section{Pembahasan}

Contextual Teaching and Learning (CTL) merupakan model pembelajaran yang menekankan pada proses keterlibatan peserta didik secara penuh untuk dapat menemukan hubungan antara materi yang dipelajari dengan realitas kehidupan nyata, sehingga mendorong peserta didik untuk menerapkankannya dalam kehidupan sehari-hari (Elainne B. Johnson, 2010: 65). CTL menyeting kelas menjadi meniatur lingkungan mini, dimana di dalamnya terjadi dialog antara teori dan praktik, atau edialitas dan realitas.

Penerapan CTL dalam proses pembelajaran menekankan pada tiga hal. Pertama CTL menekankan pada proses keterlibatan peserta didik untuk menemukan materi pelajaran, atau 
proses pengalaman secara langsung, jadi terjadi proses mencari dan menemukan sendiri materi pelajaran tersebut. Kedua, CTL mendorong agar peserta didik dapat menemukan hubungan antara materi yang dipelajari dengan realitas kehidupan nyata, sehingga tertanam erat dalam memori peserta didik. Ketiga, CTL mendorong peserta didik untuk dapat menerapkannya, mengaktualisasi dan mengkontektualisasi materi pelajaran dalam kehidupan sehari-hari.

Dengan kata lain melalui CTL materi pelajaran bukan untuk dihafal, melainkan untuk dipahami, dipraktikkan dan dibiasakan. Pengetahuan dan pengalaman dapat diaplikasikan, terjadi refleksi serta umpan balik (feedback) untuk proses perbaikan dan penyempurnaan (Hamruni, 2009: 47). Pembelajaran CTL intinya membantu guru untuk mengaitkan materi pembelajaran dengan kehidupan nyata dan memotivasi siswa untuk mengaitkan pengetahuan yang dipelajarinya dengan kehidupan mereka. (Ahmad Zayadi dan Abdul Majid,2005: 11). Pembelajaran CTL merupakan cara belajar yang terbaik dimana siswa mengkonstruksi sendiri secara aktif pemahamannya. Karena itu kebiasaan guru "akting di panggung dan siswa menonton" harus diubah menjadi "siswa aktif bekerja dan belajar di panggung", sedangkan guru membimbingnya dari dekat. Pembelajaran kontektual, pengetahuan akan bermakna pada saat pengetahuan tersebut ditemukan dan dibangun sendiri oleh siswa (Wina Sanjaya, 2008: 256).

Istilah kontektual dalam bahasa Arab disebut Al-Waqi'iyyah sebagaimana dikemukakan oleh (Dahlan, 2002: 12) mengandung makna pengakuan akan realitas alam sebagai hakikat faktual dan memiliki eksistensi yang terlihat. Yang merupakan konteks kehidupan nyata, dengan harapan siswa dapat memahami apa yang dipelajarinya, sehingga mudah diserap/ditransfer satu permasalahan ke permasalahan lain dan dari satu konteks ke konteks lainnya, menjadikan pengalaman menjadi lebih relevan dan berarti bagi siswa, diharapkan siswa belajar melalui "mengalami dan menemukan sendiri', bukan dari "apa kata guru". Menurut (Dede Rosyada, 2007: 160) belajar dengan model ini biasa disebut dengan self discovery learning, yakni belajar melalui penemuan mereka sendiri. Begitu juga (Philip, 1997: 81) mengatakan dalam proses pembahasan terhadap hasil diskusi yang diperoleh oleh masing-masing kelompok, guru terus memberikan bimbingan dan arahan terhadap siswa.

Salah satu asas yang menjadi filosofis dalam CTL adalah asas Pemodelan (Modelling). Menurut (Suyadi, 2013: 86) Asas modelling adalah proses pembelajaran dengan memperagakan sesuatu sebagai contoh yang dapat ditiru oleh setiap peserta didik. Begitu pula (Abdul Majid, 2012: 177) mengungkapkan Pemodelan adalah proses pembelajaran dengan memperagakan sesuatu sebagai contoh yang dapat ditiru oleh siswa. Pemodelan dimaksud agar dalam menerima sesuatu, siswa tidak merasa samar/kabur dan bingung, maka perlu adanya model 
atau contoh yang bisa ditiru. (Bandura, 1977: 22) mengatakan fortunately, most human behavior is learned observationality through modeling; from observing other one forms an idea of how new behaviors are performed and on lateraccasions this coded informations serves as aguide of action. Hal yang sama Neviarni (2009: 87) mengatakan peniruan merupakan suatu cara belajar berdasarkan pada hasil observasi tentang perilaku orang lain yang kemudian dijadikan pedoman untuk ditiru dan ditampilkan oleh dirinya.

Dalam pembelajaran PAI istilah pemodelan dikenal dengan istilah keteladanan. Menurut Kamus Besar Bahasa Indonesia (1995:1160). Teladan artinya sesuatu yang dapat ditiru, dicontoh tentang perbuatan, kelakuan, sikap, dan sebagainya; meneladani; mencontoh; meniru, dan keteladanan artinya hal yang dapat ditiru, dicontoh. Dalam pembelajaran PAI keteladanan merupakan metode yang cukup efektif, karena siswa dapat menyaksikan langsung sikap dan perilaku, yang ditampil oleh seorang guru. Keteladanan bagi seorang pendidik sangat berpengaruh kepada siswa dan lingkungan sekitarnya, dan dapat memberi warna yang cukup besar, bahkan mampu mengubah perilaku siswa dan masyarakat sekitarnya. Guru dipandang sebagai sumber keteladanan, karena sikap dan perilaku guru mempunyai implikasi yang luar biasa terhadap siswa.

Dalam Al Quran teladan disebut dengan uswah hasanah. Uswah atau iswah semakna dengan qudwah (ikutan), al-mitsl atau al-mitsal (panutan, contoh, model. Term uswah hasanah dalam Al Quran bermakna orang yang dijadikan model, contoh, ikutan atau teladan terbaik atau paling bagus, seperti Nabi Muhammad sebagai uswah hasanah (Q.S. Al Ahzab,[33]: 21) dan Nabi Ibrahim (Q.S.Al Muntahanah [63]: 4-6). Begitu juga guru hendaknya bisa menampilkan dirinya sebagai uswah hasanah. Model pembelajaran seperti ini dapat diterapkan untuk menjaga kelestarian lingkungan hidup.

Menjaga kelestarian lingkungan hidup merupakan kewajiban bagi manusia sebagai khalifah di bumi. Jika manusia tidak memelihara alam semesta sebagaimana seharusnya, maka manusia itulah yang menanggung dari semua akibat yang ditimbulkannya. Adapun tujuan diciptakan manusia sebagai khalifah fi-Ardh adalah untuk memakmurkan bumi dan melestarikannya untuk mewujudkan rahmat bagi alam sekitarnya(Q.S. Al-Anbiya' [21]: 107). Maka Allah melarang berbuat kerusakan di bumi (Q.S. Al-A'raf [7]: 56). Terhadap orang yang telah berbuat kerusakan agar kembali ke jalan yang benar (Q.S. Ar-Rum [30]: 41), yaitu dengan cara melestarikannya.

Dengan terjaganya lingkungan hidup, hutan yang lebat, pohon-pohon yang rindang, maka air akan tetap mengalir dan air akan menjadi suci, bersih, bening sebagai kebutuhan hidup manusia digunakan untuk minum, masak, mandi, mencuci, berwudhu'. Sebaliknya jika 
hutan diekploitir, hutan dibabat habis, maka akan timbul apa yang disebut dengan desertisasi (pengundulan), ini berarti resevoir alami air tanah menjadi hilang, maka kering-kerontonglah bumi ini, terjadi banyak erosi, laut dan sungai menjadi tercemar akibatnya terancamlah kehidupan makhluk hidup di muka bumi, hewan, binatang melata termasuk manusia.

Sebagai khalifah di bumi manusia hendaknya bertanggung jawab untuk melestarikan lingkungan hidup, berupaya untuk tidak mengekploitasi, membakar, menebang, merambah tanpa memikir dampak yang timbul, dan hendaklah memiliki etika terhadap lingkungan. Etika lingkungan merupakan cara memperlakukan lingkungan sesuai konsep ekologi. (Abdullah Ali, 1991: 69) mengatakan ekologi adalah mempelajari interaksi makhluk hidup dengan lingkungannya. Suatu sistem dimana terdapat keseimbangan ekologis, dinamakan ekosistem. Apabila ekosistem terganggu atau kita tidak menjaganya maka semua makhluk akan terbawa dampaknya. (K. Bertens, 2007: 6) mengistilahkan etika dengan moral, karena nasib lingkungan sangat tergantung pada perilaku manusia. Untuk menjaga kelestarian lingkungan harus dibiasakan serta dibudayakan. (Sukarni, 2011: 210) mengatakan antara lingkungan dan budaya memiliki hubungan dialektis yang masing-masing mempengaruhi.

Dengan terpeliharanya lingkungan hidup, kebutuhan manusia terhadap air bersih bisa terpenuhi, sampah-sampah bisa dikelola dengan baik, maka lingkungan bisa terhindar dari pencemaran, lingkunganpun akan terlihat ramah, bersih, rapi dan indah. Dengan terjaganya kebersihan, maka harapan untuk hidup sehat akan semakin besar, karena hubungan antara keduanya sangat erat. Sehat ini merupakan kenikatan yang sangat besar, Sabda Rasulullah Saw: "Ada dua kenikmatan yang kebanyakan manusia terhitung rugi dalam menggunakan keduanya, yaitu: kesehatan dan waktu kosong" (H.R. Bukhari dari Ibnu Abbas Ra).

\section{PENUTUP}

1. Keunggulan model CTL dapat meningkatkan aktivitas, kemandirian siswa dalam mencari materi yang dipelajari, serta mampu menggali, berdiskusi, memahami, serta menerapkan dalam kehidupan sehari-hari.

2. Lingkungan hidup terdiri dari biotik dan nonbiotik yang sangat bermanfaat bagi kehidupan makhluk hidup. Upaya melestarikan dengan cara menanam kembali, tidak mengeksploitasi, menebang, merambah, dan membakar. Penggunaan harus sesuai dengan etika lingkungan.

3. Penerapan model pembelajaran kontektual dalam pembelajaran PAI secara umum telah berhasil mengaktifkan, mendinamiskan siswa untuk mencari dan menemukan sendiri materi, menguasai, memahami teori atau sumber bacaan, kemudian bertanya dan 
berdiskusi, serta mampu mengorelasikan dengan kehidupan nyata, siswa termotivasi untuk menerapkan, mengaktualisasi dalam kehidupan sehari-hari.

4. Guru PAI beserta warga MAN 1 sudah dapat menunjukkan salah satu asas yang menjadi landasan filosofis CTL yaitu menjadi pemodelan (modelling), panutan, uswatun hasanah, atau contoh yang baik dalam melestarikan lingkungan hidup, yang dibuktikan dengan terpeliharanya pohon-pohon pelindung, kebersihan dan keindahan, serta terciptanya lingkungan yang sehat.

\section{REFERENSI}

Ali, Abdullah \& Rahma, Eny. (1991). Ilmu Alamiah Dasar. Jakarta: Bumi Aksara.

Bertens, K. (2007). Etika. Jakarta: Gramedia Utama.

Dahlan, M.D. (2002). Kajian Analitik Tentang Karakteristik Pendidikan Islam. Bandung: Fakultas Tarbiyah UNISBA

Hamruni. (2009). Strategi dan Model-model Pembelajaran Aktif Menyenangkan. Yogyakarta: Fakultas Tarbiyah UIN Sunan Kalijaga.

Johnson, Elaine B. (2010). Contextual Teaching \& Learning Menjadikan Kegiatan Belajar Mengajar dan Bermakna. Bandung: Kaifa.

Mahmud. (2011). Metode Penelitian Pendidikan. Bandung: Pustaka Setia

Majid, Abdul. (2012). Belajar dan Pembelajaran Pendidikan Agama Islam. Bandung: Remaja Rosdakarya.

Philips,Sally. (1997). Opportunities and Responsibilities: Competence,Creativity, Collaboration, and Caring, dalam, John K. Roth,Inspiring Teaching, Anker Publishing Company, USA.

Rosyada, Dede. (2007). Paradigma Pendidikan Demokrasi Sebuah Model Pelibatan Masyarakat dalam Penyelenggaraan Pendidikan. Jakarta: Kencana.

Suyadi. (2013). Strategi Pembelajaran Pendidikan Karakter. Bandung: Remaja Rosdakarya.

Sukarni. (2011). Fikih Lingkungan Hidup. Jakarta: Kementerian Agama RI. 
Wina Sanjaya. (2008). Strategi Pembelajaran Berorientasi Standar Proses Pendidikan. Jakarta: Kencana Persada Media Group.

Zayadi, Ahmad \& Majid, Abdul. (2005). Tadzkirah Pembelajaran Pendidikan Agama Islam (PAI) Berdasarkan Pendekatan Kontektual. Jakarta: Raja Grafindo Persada. 